\title{
Analysis of maternal mortality at tertiary care centre
}

\author{
Hemalatha S. V.*1, Manickadevi M. S. ${ }^{2}$
}

\begin{abstract}
${ }^{1}$ Department of Obstetrics and Gynecology, Government Chengalpattu Medical College, Tamil Nadu, India ${ }^{2}$ Department of Obstetrics and Gynecology, Government RSRM Lying in Hospital, Royapuram, Chennai, Tamil Nadu, India
\end{abstract}

Received: 21 October 2021

Revised: 14 November 2021

Accepted: 15 November 2021

\section{*Correspondence:}

Dr. Hemalatha S. V.,

E-mail: svhemak@gmail.com

Copyright: (C) the author(s), publisher and licensee Medip Academy. This is an open-access article distributed under the terms of the Creative Commons Attribution Non-Commercial License, which permits unrestricted non-commercial use, distribution, and reproduction in any medium, provided the original work is properly cited.

\section{ABSTRACT}

Background: The aim of the study was to analyse the causes of maternal mortality at a tertiary care centre and find measures to reduce it.

Methods: A retrospective study of maternal deaths from January 2018 to December 2020 that occurred at Government Vellore Medical College and Hospital, a tertiary care hospital in Tamil Nadu. Data collected from case records and death reviews.

Results: There was total of 71 deaths at the tertiary care hospital during the period January 2018 to December 2020 out of 31407 live births giving Maternal mortality rate of 226/1,00,000 live births. The MMR is high as it is a tertiary hospital catering referral from six districts. Most of the cases were due to late referrals. The majority of the deaths occurred in primigravida $(50.7 \%)$, in the age group of 21 to 25 years $(35.2 \%)$ and around term gestational age (49.3\%). The most common cause of death in our study was hypertensive disorders of pregnancy $(29.5 \%)$ followed by PPH $(14.08 \%)$.

Conclusions: From our study we concluded that the most common causes of maternal death were due to direct obstetric causes like severe pre-eclampsia, eclampsia and post-partum haemorrhage. Early identification of high-risk cases, early identification of GHT, anaemia and its correction, early referral of high-risk cases to tertiary centre can prevent most of the deaths.

Keywords: Maternal mortality, High risk, Obstetric causes

\section{INTRODUCTION}

Maternal mortality in a region is a measure of the reproductive health of a woman in the area and the quality of the health care delivery system. ${ }^{1}$

According to WHO, 'maternal mortality is defined as death of a woman while pregnant or within 42 days of termination of pregnancy irrespective of duration and site of the pregnancy, from any cause related to or aggravated by the pregnancy or its management but not from accidental or incidental causes. ${ }^{1}$ Globally 5,00,000 women die due to pregnancy related causes and $99 \%$ of these are in developing countries. ${ }^{2}$ Sub-saharan Africa accounted for $67 \%$ and South Asia $24 \% .^{2}$ India and Nigeria account for one-third of the maternal deaths. ${ }^{3}$ Global maternal mortality reduced by $38 \%$ between 2000 and 2017 (from 242 to $211 / 1,00,000$ live births) according to UN interagency estimates. Among the various states in India, Assam has the highest MMR of 215/1,00,000 live births and among Southern states Kerala has least MMR of 45/1,00,000 live births and Tamil Nadu it was 60/1,00,000 in the year 2016-2018. ${ }^{1}$

Maternal mortality is classified according to WHO into(1) obstetric causes- (a) direct obstetric causes, and (b) indirect obstetric causes; and (2) non-obstetric causes. Direct maternal death is the death of the mother that results 
from obstetrical complications of pregnancy, labour or the puerperium and from the intervention, omissions, inadequately managed or a chain of events resulting from any of these factors e.g. gestational hypertension, antepartum hemorrhage, post-partum haemorrhage, obstructed labour, rupture uterus, septic abortion, puerperal sepsis, complications of anaesthesia, surgical complications following LSCS, PPCM, etc.

Indirect maternal death is the maternal death that is not directly due to an obstetrical cause. Death results from preexisting disease or disease developing during pregnancy, labour or puerperium or condition aggravated by maternal physiological adaptation in pregnancy e.g. heart disease complicating pregnancy, anaemia in pregnancy, infectitious diseases, liver disorders, acute and chronic renal failure, epilepsy, haematological causes, etc.

Non-obstetric causes- e.g. accident, suicide, assault, snake bite, non-obstetric surgical cause etc. Indicators of maternal mortality are Maternal mortality ratio (MMR) and maternal mortality rate.

Maternal mortality rate is the number of maternal deaths per 1000 women of reproductive age group (15-49 years).

Maternal mortality ratio is the number of maternal deaths during a given period of time per 1,00,000 live births during the same period. MMR is the key indicator of maternal mortality.

$$
M M R=\frac{\text { Total no. of maternal death }}{\text { Total no. of live births }} \times 100000
$$

According to Sample registration system (SRS) Bulletin 2016-2018 MMR in India was 113 and Tamil Nadu was $60 / 100000$ live births. $^{1}$ According to this bulletin maximum deaths occurred in age groups 20-24 years $(33 \%)$.

The target of Sustainable Development Goals (SDG) set by United Nations aims at reducing the global maternal mortality ratio to less than 70/100000 live births. ${ }^{1,4}$

The maternal mortality ratio in India has declined from $130 / 1,00,000$ live births in $2014-2016$ to $122 / 1,00,000$ live births in $2015-2017$ to $113 / 1,00,000$ live births in 20162018. ${ }^{1,5}$

The Maternal death review (MDR) was initiated by Government of India in 2010 to improve the quality of obstetric care and reduce maternal mortality by exploring the lacunae in the health system.

The MDR provides detailed analysis on various factors at community, facility, district, regional and national level to reduce maternal deaths. The guidelines of MDR is revised with focus on surveillance, response and a component of confidential review has been incorporated. ${ }^{6}$
This study was done to analyse the causes of maternal death, factors responsible for it, whether preventable and health care improvement needed to avoid the maternal death. Most of these causes are preventable by early detection of high-risk factors, early referral to higher centre and early intervention can reduce MMR.

The causes of maternal death according to UNICEF data September 2019 are haemorrhage accounting for $27 \%$, hypertensive disorders- $14 \%$, sepsis- $11 \%$, indirect causes$28 \%$, abortions- $8 \%$, embolism- $3 \%$, other direct causes$10 \%{ }^{7}$ About $20 \%$ of maternal death are due to indirect obstetric causes.

\section{METHODS}

A retrospective study of maternal deaths at Government Vellore Medical College Hospital, Vellore, Tamil Nadu from January 2018 to December 2020. It is a tertiary care hospital catering 6 districts. Cases are referred from district hospitals, sub district hospitals and PHC. Data were collected from the case sheets and maternal death review forms. Total of 71 deaths occurred during this period. Every maternal death was analyzed with respect to age, parity, condition of patient on admission, admission death interval, cause of death and preventable factors.

\section{Inclusion criteria}

All the maternal deaths that occurred in the institute from January 2018 to December 2020 were included irrespective of age, parity, booking status.

\section{Exclusion criteria}

Maternal deaths from suicide and brought dead cases were excluded.

\section{Statistical analysis}

Data was entered and analysed using Microsoft excel 2013.

\section{RESULTS}

During the period of study from January 2018 to December 2020 there were 71 maternal deaths out of 31,407 live births giving an MMR of 226/1,00,000 live births (Table 1) MMR is high because it is a tertiary centre with high risk late referrals.

The epidemiological characteristics of maternal death is shown in Table 2.

It was observed in our study that maximum deaths 25 cases (35.2\%) were in age group of 21-25 years, followed by 17 cases $(23.9 \%)$ in $26-30$ years, 14 cases $(19.7 \%)$ in $<20$ years and there were 15 deaths $(21.1 \%)$ in age group above 30 years. 
Most of these deaths 36 cases $(50.7 \%)$ were primigravida, second gravida 18 cases $(25.35 \%)$, and third gravida 15 cases $(21.2 \%)$. Of the 71 maternal deaths 60 cases $(84.5 \%)$ were referred cases. Most of these referrals were from $\mathrm{GH}$ $(42.2 \%)$ and PHC (36.6\%). $87.5 \%$ of these deaths were in post-natal period, $9.8 \%$ during $\mathrm{AN}$ period and $5.6 \%$ were ectopic pregnancy. Of the postnatal deaths 35 cases $(49.3 \%)$ was term delivery, 23 cases $(32.4 \%)$ delivered between $28-37$ weeks and 7 cases $(9.8 \%)$ between 14-28 weeks. Maximum post-natal deaths $70 \%$ occurred $>24$ hours post-partum and $30 \%$ occurred in $<24 \mathrm{hrs}$. Almost all patients $98.3 \%$ were institutional delivery except for 1 home delivery. 37 cases $(61.6 \%)$ were delivered by LSCS, 17 cases $(28.3 \%)$ by labor natural, 2 cases $(3.33 \%)$ by instrumental delivery and 4 cases $(6.66 \%)$ by spontaneous expulsion. Regarding condition of patient on admission,
44 cases $(61.9 \%)$ were stable and 27 cases $(38 \%)$ were received in moribund state.

In our study $71.8 \%$ of cases were due to direct obstetric causes, $25.3 \%$ of cases were due to indirect obstetric causes and $2.8 \%$ of cases due to non-obstetric causes. Preeclampsia and eclampsia was the most common direct cause of maternal death 21 cases $(29.48 \%)$ followed by PPH 10 cases (14\%), sepsis 4 cases (5.63\%), ectopic pregnancy 4 cases $(5.63 \%)$ and 1 case due to complication of bowel injury during LSCS.

Among indirect causes heart disease was most common cause 8 cases $(11.26 \%$ ), followed by anaemia 5 cases $(7.04 \%)$, respiratory failure 4 cases $(5,63 \%)$ and 1 case of hepatic encephalopathy.

Table 1: Total deliveries, death and MMR at the tertiary care hospital.

\begin{tabular}{|llll|}
\hline Year & Total deliveries & Maternal deaths & MMR \\
\hline $\mathbf{2 0 1 8}$ & 11853 & 18 & 151.86 \\
\hline $\mathbf{2 0 1 9}$ & 9435 & 22 & 233.17 \\
\hline $\mathbf{2 0 2 0}$ & 10119 & 31 & 306.35 \\
\hline Total & 31407 & 71 & 226 \\
\hline
\end{tabular}

Table 2: Socio-demographic characteristics.

\begin{tabular}{|c|c|c|c|}
\hline Characteristics & Groups & No. of maternal deaths $(\mathrm{N}=71)$ & Percentage $(\%)$ \\
\hline \multirow{4}{*}{ Age (years) } & $<20$ & 14 & 19.7 \\
\hline & $21-25$ & 25 & 35.2 \\
\hline & $26-30$ & 17 & 23.9 \\
\hline & $>30$ & 15 & 21.1 \\
\hline \multirow{4}{*}{ Parity } & 1 & 36 & 50.7 \\
\hline & 2 & 18 & 25.35 \\
\hline & 3 & 15 & 21.12 \\
\hline & 4 & 2 & 2.8 \\
\hline \multirow{2}{*}{ Referral status } & Referred & 60 & 84.5 \\
\hline & No referral & 11 & 15.5 \\
\hline \multirow{4}{*}{ Referral } & PHC & 26 & 36.6 \\
\hline & GH & 30 & 42.2 \\
\hline & $\mathrm{MC}$ & 2 & 2.8 \\
\hline & Private Hospital & 2 & 2.8 \\
\hline \multirow{5}{*}{$\begin{array}{l}\text { Gestational age } \\
\text { (weeks) }\end{array}$} & Term & 35 & 49.3 \\
\hline & $28-37$ & 23 & 32.4 \\
\hline & $14-28$ & 7 & 9.8 \\
\hline & $<14$ & 4 & 5.6 \\
\hline & Ectopic & 2 & 2.8 \\
\hline \multirow{2}{*}{ Admission status } & Stable & 44 & 61.9 \\
\hline & Poor & 27 & 38.02 \\
\hline \multirow{3}{*}{ Period of death } & $\mathrm{AN}$ & 7 & 9.85 \\
\hline & PN & 60 & 84.5 \\
\hline & Ectopic & 4 & 5.6 \\
\hline
\end{tabular}

Table 3: Characteristics of maternal deaths.

\begin{tabular}{|llll|}
\hline Characteristics & Groups & No. of maternal deaths & Percentage (\%) \\
\hline \multirow{3}{*}{ Place of delivery } & Institutional & 59 & 98.3 \\
& Home & 1 & 1.66 \\
\hline
\end{tabular}




\begin{tabular}{|llll|}
\hline Characteristics & Groups & No. of maternal deaths & Percentage (\%) \\
& GH & 10 & 16.6 \\
\cline { 2 - 4 } Route of delivery & MC & 45 & 75 \\
\hline \multirow{4}{*}{$\begin{array}{l}\text { Delivery to death } \\
\text { interval (hours) }\end{array}$} & LN & 17 & 28.3 \\
& LSCS & 37 & 61.6 \\
\cline { 2 - 4 } & Instrumental & 2 & 3.33 \\
\cline { 2 - 4 } & Spontaneous expulsion & 4 & 6.66 \\
\hline $\begin{array}{l}\text { Post-natal deaths } \\
\text { (hours) }\end{array}$ & -6 & 6 & 10 \\
\hline & $7-12$ & 9 & 15 \\
\hline & $25-48$ & 5 & 8.3 \\
\hline & $>48$ & 14 & 23.3 \\
\hline
\end{tabular}

Table 4: Causes of maternal death.

\begin{tabular}{|lll|}
\hline Causes & No. of deaths & Percentage (\%) \\
\hline Direct obstetric cause & 51 & 71.8 \\
\hline Indirect obstetric cause & 18 & 25.35 \\
\hline Non-obstetric cause & 2 & 2.8 \\
\hline
\end{tabular}

Table 5: Causes of maternal death.

\begin{tabular}{|lllllllll|}
\hline & $\mathbf{2 0 1 8}$ & $\mathbf{3}$ & $\mathbf{2 0 1 9}$ & $\mathbf{2 0 2 0}$ & \multicolumn{3}{c|}{ Total } \\
\hline Pre-eclampsia & $\mathbf{N}$ & $\mathbf{\%}$ & $\mathbf{N}$ & $\mathbf{\%}$ & $\mathbf{N}$ & $\mathbf{\%}$ & $\mathbf{N}$ & $\mathbf{\%}$ \\
\hline Eclampsia & 3 & 16.6 & 2 & 9.09 & 6 & 19.3 & 11 & 15.4 \\
\hline PPH & 3 & 16.6 & 3 & 13.6 & 4 & 12.9 & 10 & 14.08 \\
\hline Placenta previa & 1 & 5.5 & 4 & 18.8 & 5 & 1.61 & 10 & 14.08 \\
\hline Sepsis & - & - & - & - & 2 & 6.44 & 2 & 2.8 \\
\hline CVA & - & - & 2 & 9.09 & 2 & 6.44 & 4 & 5.6 \\
\hline Ectopic & 1 & 5.5 & - & - & 2 & 6.44 & 3 & 4.22 \\
\hline Pulmonary embolism & 1 & 5.5 & 2 & 9.09 & 1 & 3.22 & 4 & 5.6 \\
\hline Amniotic fluid embolism & - & - & 1 & 4.54 & 1 & 3.22 & 2 & 2.8 \\
\hline Heart disease & 1 & 5.5 & 1 & 4.54 & 2 & 6.44 & 4 & 5.6 \\
\hline Anaemia & 2 & 11.1 & 3 & 13.6 & 3 & 9.69 & 8 & 11.26 \\
\hline Respiratory failure & 2 & 11.1 & 1 & 4.54 & 2 & 6.44 & 5 & 7.04 \\
\hline Hepatic encephalopathy & 3 & 16.6 & 1 & 4.54 & - & - & 4 & 5.6 \\
\hline Surgical complication (bowel injury) & - & - & - & - & 1 & 3.22 & 1 & 1.4 \\
\hline RTA & - & - & 1 & 4.54 & - & - & 1 & 1.4 \\
\hline Snake bite & 1 & 5.5 & - & - & - & - & 1 & 1.4 \\
\hline
\end{tabular}

\section{DISCUSSION}

Maternal mortality is an index of reproductive health of the society. Maternal mortality ratio in our study was $226 / 100000$ live births. MMR is high because most of the cases about $84.5 \%$ were referred from various district hospitals and PHCs. Delayed referral was an important contributing factor and also $38.02 \%$ of cases were received in a moribund state.

According to Sample Registration System (SRS) bulletin 2016-2018, the MMR of India declined from 130 in 201416 to 122 in $2015-17$ to 113 in 2016-18. ${ }^{1}$ The MMR in Tamil Nadu declined from 66/1,00,000 live births in 201416 to 63 in $2015-17$ and 60 in $2016-18$ as per data maintained by SRS, Government of India. ${ }^{1}$
In our study most of the deaths occurred in age group of 21-25 years $(35.2 \%)$ which correlates with other studies and in primigravida $(50 \%)$ compared to other studies where deaths were more common with multigravida. Deaths in postnatal period occurred in $84.5 \%$ of cases in our study compared to $92.5 \%$ in other studies. ${ }^{8}$

Maximum deaths (70\%) occurred after 48hours postpartum in our study which correlates with studies by Sureka et al. ${ }^{9}$

Under NHM various steps are taken to reduce the maternal deaths. One of this is JSY (Janani Suraksha Yojana)objective of JSY is encouraging institutional deliveries there by reducing MMR. ${ }^{10}$ In our study all cases were 
institutional deliveries except 1 case of home delivery. Of the institutional deliveries $61.6 \%$ were delivered by LSCS and $28.3 \%$ by vaginal deliveries. Though all were institutional deliveries delayed referral to tertiary centre was the cause for increased MMR.

Under JSSK scheme (Janani Shishu Suraksha Karyakram) every pregnant woman is entitled to free delivery including LSCS in public health institute, free transport, diagnostics, medicines, food and blood products. This was also to facilitate institutional delivery. ${ }^{10}$

Pre-eclampsia and eclampsia accounted for 21 cases (29.48\%) in our study which was consistent with studies by Sundari et al and Khandale et al. ${ }^{8,9}$ Early identification of GHT needs to be emphasized during AN check-up. Early referral, use of magnesium sulphate and early termination can prevent deaths due to complications of GHT.

The second common cause of MMR in our study was PPH 10 cases $(14.08 \%)$ compared to $10 \%$ in study by Khandale et al and $17 \%$ in study by Sundari et al. ${ }^{8,9}$ Ensuring availability of blood and blood products, early identification of PPH, early transfusion and early referral to tertiary centre can prevent such deaths. The deaths due to haemorrhage can be reduced by conducting programmes like Skilled birth attendant training (SBA) of the medical officers, staff nurses, VHN at PHC and GH level.

Death due to sepsis was $5.6 \%$ in our study compared to $12.5 \%$ in the study by Sundari et al. ${ }^{8}$ LaQshya- labour room quality improvement initiative was launched in 2017 to improve the quality of the services there by help in reduction of MMR. ${ }^{10}$

Access to family planning services especially abortion care services can reduce deaths due to septic abortions. The deaths due Ectopic pregnancy in our study was 4 cases (5.63\%). Early diagnosis and prompt treatment help in preventing such deaths.

Among the indirect obstetric causes the most common cause in our study was heart disease in pregnancy 8 cases $(11.26 \%)$ consistent with studies by Sudha et al. ${ }^{11}$ To reduce the maternal death due to heart disease, the Tamil Nadu pregnancy and heart disease registry was created and pregnant patients with heart disease were followed throughout pregnancy and upto 6 weeks postpartum.

The second common cause among indirect cause was anaemia complicating pregnancy about $7.04 \%$ compared to $14 \%$ in study by Khandale et al, $41.7 \%$ in study by Arpita et al and $53.57 \%$ by Sundari et al. ${ }^{8,12}$

National iron plus initiative launched by Ministry of Health and Family Welfare in 2013 insists on Iron supplementation to all adolescent girls, pregnant and lactating women. Other indirect obstetric causes in our study were respiratory failure in 5 cases $(7.04 \%)$ and 1 death was due to hepatic encephalopathy.

Non-obstetric causes in our study was 1 case of snake bite and 1 case of road traffic accident. Various programs were launched by government to reduce maternal and newborn deaths.

PMSMA (Pradhan Mantri Surakshit Matritva Abhiyan) was launched by Ministry of Health and Family welfare, Government of India. This program aims to provide assured comprehensive and quality AN care free of cost universally to all pregnant women on $9^{\text {th }}$ of every month. Special AN care is provided by obstetrician, physician and radiologist apart from routine AN care by obstetrician. ${ }^{10}$

Ministry of Health and family welfare (MOHFW), GOI has developed an initiative termed Dakshata to reduce the MMR and newborn mortality by improving quality of care at delivery points through training of medical officers for competency enhancement.

During COVID pandemic, Mentoring concept was launched by NHM Tamil Nadu in December 2019. HOD of $\mathrm{O}$ and $\mathrm{G}$ department in Government medical colleges/district headquarters hospital were designated as chief district obstetrician. Each obstetrician mentored a block covering low and high-risk mothers. Under this line list of all the mothers were obtained and categorized as low risk or high risk and shared to chief district obstetrician for opinion. This concept included both direct mentoring at district level and virtual mentoring by linking to medical college hospitals.

This concept enabled to provide proper interventional services at right time to ensure safe delivery, also picked up high risk mothers early enabling admission 10 days prior to EDD.

Further government has initiated vaccination against COVID for pregnant and lactating mothers to prevent maternal mortality due to COVID.

There were few limitations of our study, being conducted in one tertiary care hospital only and period of study lasting for 3 years.

Table 6: MMR in India and Tamil Nadu from 2016 to 2018.

\begin{tabular}{|lll|l|}
\hline MMIR & $2014-2016$ & $2015-2017$ & $2016-2018$ \\
\hline India & 130 & 122 & 113 \\
\hline $\begin{array}{l}\text { Tamil } \\
\text { Nadu }\end{array}$ & 66 & 63 & 60 \\
\hline
\end{tabular}

\section{CONCLUSION}

Through this study we conclude that hypertensive disorders of pregnancy and its complications are the most important cause of maternal death followed by PPH. All 
these are preventable causes. Due to multifactorial nature of maternal death strategies should involve staff from grass root level. Good AN care, early identification of high-risk cases, appropriate treatment in peripheral hospitals, early referral and team approach for management of high-risk cases helps in reducing MMR. Health education of pregnant mothers regarding warning signs in pregnancy, training of medical officers and staff nurses like SBA, good quality health care ensuring availability of essential drugs like magnesium sulphate, tablet misoprostol and availability of ambulance services round the clock helps in reducing MMR.

\section{Funding: No funding sources}

Conflict of interest: None declared

Ethical approval: The study was approved by the Institutional Ethics Committee

\section{REFERENCES}

1. Government of India. Special bulletin on maternal mortality in India 2016-18: Sample registration system, 2016. Available at: https://censusindia.gov.in/vital_statistics/SRS_Bullet ins/MMR\%20Bulletin\%202016-18.pdf. Accessed on 12 October 2021.

2. Singla A, Rajaram S, Mehta S, Radhakrishnan G. A Ten Year Audit of Maternal Mortality: Millennium Development Still a Distant Goal. Indian J Community Med. 2017;42(2):102-6.

3. WHO. Trends in maternal mortality: 1990 to 2015 Estimates by WHO, UNICEF, UNFPA, World Bank Group and the United Nations Population Division. WHO: Geneva; 2015.

4. WHO. The global health observatory, 2021. Available at: https://www.who.int/data/gho/indicator-metadataregistry/imr-details/26. Accessed on 12 October 2021.

5. Government of India. SRS Bulletin-MMR, 2017. Available
https://censusindia.gov.in/vital_statistics/SRS_Bullet ins/MMR-Bulletin2015-2017. Accessed on 12 October 2021.

6. Ministry of Health and family welfare. Guidelines for maternal death surveillance and response 2017, 2017. Available at: https://nhm.gov.in/images/pdf/programmes/maternalhealth/guidelines/Guideline_for_MDSR. Accessed on 12 October 2021.

7. WHO. Trends in maternal mortality 2000 to 2017 : estimates by WHO, UNICEF, UNFPA, World Bank Group and the United Nations Population Division: executive summary, 2019. Available at: https://apps.who.int/iris/handle/10665/3. Accessed on 12 October 2021.

8. Mohana KP, Padma SR, Subathra P. Maternal mortality: analysis of causes and preventable factors. Int J Reprod Contracept Obstet Gynecol. 2016;5(6):1719-21.

9. Khandale SN, Kedar K. Analysis of maternal mortality: a retrospective study at tertiary care centre. Int J Reprod Contracept Obstet Gynecol. 2017;6(4):1610-3.

10. Government of India. Maternal and adolescent health care annual report 2019-2020, 2020. Available at: https://main.mohfw.gov.in/sites/default/files/Annual $\% 20$ Report\%202019-2020. Accessed on 12 October 2021.

11. Sivakumar S, Xavarina SG, Srianand A. Maternal death audit at tertiary care centre: changing trends. Int J Reprod Contracept Obstet Gynecol. 2012;10(3):915-9.

12. Ballu AS, Asha MB. A comprehensive study on maternal mortality at a tertiary care hospital. Indian $\mathbf{J}$ Obstet Gynaecol Res. 2019;6(3):259-62.

Cite this article as: Hemalatha SV, Manickadevi MS. Analysis of maternal mortality at tertiary care centre Int J Reprod Contracept Obstet Gynecol. 2021;10:4454-9. 